\title{
Anabases
}

ANABASES Traditions et réceptions de l'Antiquité

$1 \mid 2005$

Varia

\section{Bruno TOPPAN (ss la dir.), Rome. Mythes et symboles}

\section{Philippe Foro}

\section{OpenEdition \\ Journals}

Édition électronique

URL : http://journals.openedition.org/anabases/1517

DOI : 10.4000/anabases. 1517

ISSN : 2256-9421

\section{Éditeur}

E.R.A.S.M.E.

\section{Édition imprimée}

Date de publication : 1 mars 2005

Pagination : 315-316

ISSN : 1774-4296

Référence électronique

Philippe Foro, «Bruno toppan (ss la dir.), Rome. Mythes et symboles », Anabases [En ligne], 1 | 2005, mis en ligne le 01 octobre 2011, consulté le 22 septembre 2020. URL : http://journals.openedition.org/ anabases/1517 ; DOI : https://doi.org/10.4000/anabases.1517

Ce document a été généré automatiquement le 22 septembre 2020.

(c) Anabases 


\title{
Bruno topPAN (ss la dir.), Rome. Mythes et symboles
}

\author{
Philippe Foro
}

\section{RÉFÉRENCE}

Bruno toppan (ss la dir.), Rome. Mythes et symboles, Université de Nancy 2, P.R.I.S.M.I., 4

(2001 [=2003]), $351 \mathrm{p}$.

$18 € /$ ISSN 1270-9530

1 C'est en 2001 que B. Toppan regroupa quinze contributions autour du thème des mythes et des symboles véhiculés par Rome et les fit publier deux ans plus tard. L'essentiel des contributions touche au domaine littéraire mais, par l'intermédiaire de ce dernier, le propos aborde la politique, la religion, l'esthétique, la manière de concevoir le passé et le futur au travers du prisme de Rome. Il ressort de la lecture du recueil que la Ville Éternelle est bien cette auberge espagnole où tout un chacun va chercher ce qu'il souhaite trouver, imaginer, concevoir.

En premier lieu, une référence historique et un modèle que l'on souhaite approcher, thème dominant des contributions. Les entrées royales ou impériales, étudiées par Juan Carlos D'Amico, utilisent tout le symbolisme de la Rome antique. Ainsi, quand Charles Quint entre à Bologne en 1529, des statues de César, d'Auguste, de Titus, de Trajan ornent le parcours du souverain Habsbourg, faisant de lui l'héritier des Césars. Afin de pousser plus loin l'analogie, on va jusqu'à édifier un temple de Janus afin de faire de l'empereur le maître de la paix et de la guerre. L'époque contemporaine n'est pas avare de ces liens avec la grandeur impériale. L'Italie de Francesco Crispi (1887-1896), analysée par Laura Fournier, utilise à plein la référence antique afin de mettre en parallèle les Romains et les Italiens, les victoires romaines et les expéditions italiennes, méthode reprise au moment de la guerre de Libye (1911-1912) et à l'époque fasciste. L'étude de Paul Colombani concernant l'écrivain nationaliste Enrico Corradini, montre la volonté de légitimer d'éventuelles conquêtes italiennes par l'histoire romaine, car 
Rome est une «mère-nation» selon l'expression utilisée par le poète Ippolito Nievo. Ainsi, la Dalmatie doit revenir à l'Italie puisque l'on y trouve les vestiges du palais de Dioclétien à Split. De même, les grands personnages de l'histoire romaine servent à Corradini à éclairer l'actualité italienne du moment. Sa pièce de théâtre "Jules César ", écrite en 1902 puis réaménagée en 1926 (donc après l'accession au pouvoir de Benito Mussolini), est une diatribe contre le parlementarisme et les bassesses supposées de l'Italie libérale représentée au début du XX $\mathrm{XX}^{\mathrm{e}}$ siècle par Giovanni Giolitti. Ce procédé se retrouve chez Giosuè Carducci, dont l'œuvre est présentée par Myriam Carminati, pour qui la grandeur romaine est un reproche venu du fond des siècles envers l'Italietta de son temps. Or, "le dernier fils d'Homère", selon les termes de Benedetto Croce, remarque amèrement que peu de personnes connaissent le sens des monuments antiques et qu'une touriste britannique est obligée de lire le Baedeker pour comprendre les thermes de Caracalla (" Dinanzi alle terme di Carcalla ").

Outre l'Empire et la grandeur romaine, la République est également mythifiée. Pour Pétrarque, Cola di Rienzo, le tribun populaire des années 1350, est assimilé à Brutus qui chassa de Rome le roi Tarquin le Superbe en 509 av. J.-C. L'humaniste florentin Leonardo Bruni, dans sa Vie de Cicéron, attaque Marc-Antoine et Octave comme fossoyeurs des libertés républicaines. Le grand Érasme lui-même, dans sa dédicace à l'édition de l'Histoire Auguste, critique l'Empire au profit de la République. À cet égard, Théa Piquet souligne combien, pour le Florentin Donato Giannotti (1492-1573), « sa foi républicaine s'appuie sur l'exemple de la Rome antique", faisant de Brutus et de Scipion l'Africain des hommes de grande vertu, de Cicéron un modèle.

4 Le rôle de Rome dans l'histoire du christianisme est un autre aspect abordé dans le recueil. Juan Carlos D'Amico montre d'ailleurs le lien clairement établi entre la Rome des Césars et la Rome chrétienne par Dante qui, dans son $\mathrm{VI}^{\mathrm{e}}$ chant du Paradis, estime que Dieu a favorisé César et Auguste afin de faire régner un seul monarque dans un monde unifié et en paix au moment de la venue du Christ parmi les hommes. La Rome pontificale est cependant un repoussoir pour les intellectuels patriotes du XIXe siècle. Analysant les sonnets écrits par Giuseppe Gioacchino Belli entre 1828 et 1847, Gérard Luciani souligne, outre les témoignages qu'ils sont sur le petit peuple de Rome, combien ils stigmatisent par des sarcasmes l'administration des papes Pie VIII et Grégoire XVI, se plaçant ainsi dans une lignée "stendhalienne ». Aussi, l'image de Rome se dédouble avec une Rome catholique et une Rome patriote et unitaire magnifiée lors des célébrations du $25^{\mathrm{e}}$ anniversaire (1895) de l'entrée des troupes royales dans la Ville Éternelle, mêlant patriotisme officiel et anti-cléricalisme militant. Mais l'universalisme de la Rome catholique peut être récupéré au service de la Nation italienne, ce que fit Corradini, afin de créer un lien entre l'Antiquité et l'Italie moderne.

5 Dernier objet de réflexion, Rome comme symbole d'un monde passé. C'est bien, dans l'esprit du poète Marinetti qu'étudie Jean-Philippe Bareil, la tare majeure de la Ville. Pour le fondateur du futurisme qui l'exprime dans "Contro Roma passatista ", Rome est le symbole du passé vis-à-vis d'une cité comme Milan, ville de la modernité. Rejetant les arts établis, les musées, le goût «bourgeois ", le futurisme accuse Rome de n'être plus qu'une ville-musée, croulant sous le poids de son propre passé. «Cette ville est un musée et un sépulcre où subsistent dans le silence les formes passées de la vie » écrivait déjà Ernest Renan dans ses carnets de voyage (voir la contribution de Jean Lacroix, « La Rome du XIX siècle d'Ernest Renan à André Suarès »). 
6 La publication du Programme de recherche interdisciplinaire sur le Monde Italien (P.R.I.S.M.I) se situe dans la prolongation du bel ouvrage d'Andrea Giardina et André Vauchez publié chez Fayard en 2000, Rome, l'idée et le mythe du Moyen-Âge à nos jours. Il affine le problème historique de la perception de Rome et de l'utilisation de son histoire, de ce mythe, terme qu'utilise également Dominique Fernandez dans Le voyage d'Italie à propos de Rome, apportant sa pierre à la réflexion d'une question riche et complexe mais qui touche à un élément essentiel de la culture italienne et européenne.

\section{AUTEURS}

\section{PHILIPPE FORO}

Université de Toulouse-Le Mirail 